\title{
EFEKTIVITAS PEMBELAJARAN INKUIRI TERBIMBING DALAM FISIKA PADA PESERTA DIDIK KELAS XI MIPA SMA NEGERI 3 MAKASSAR
}

\author{
Reni Ruanti ${ }^{1}$, Nurhayati ${ }^{2}$, $\mathrm{Helmi}^{3)}$ \\ Program Studi Pendidikan Fisika, Jurusan Fisika \\ Email: reniruanti917@gmail.com
}

\begin{abstract}
Abstrak. Penelitian ini merupakan penelitian True Experiment Design dengan desain Posstest-Only Contol Design. Penelitian ini bertujuan untuk mendeskripsikan skor hasil belajar pada aspek kognitif dengan empat indikator yaitu pengetahuan, pemahaman, penerapan dan analisis, antara peserta didik yang diajar dengan pembelajaran berbasis inkuiri terbimbing dan yang diajar secara konvensional, serta menganalisis perbedaan hasil belajar peserta didik yang diajar dengan pembelajaran berbasis inkuiri terbimbing dan yang diajar secara konvensional. Penelitian ini dilaksanakan di SMA Negeri 3 Makassar dengan sampel yaitu kelas XI MIPA 3 (kelas eksperimen) diterapkan pembelajaran inkuiri terbimbing dan XI MIPA 4 (kelas kontrol) diterapkan pembeajaran secara konvensional.. Hasil analisis deskriptif tes hasil belajar fisika peserta didik diperoleh skor rata-rata pada kelas eksperimen yaitu 12,79 dengan kategori tinggi, sedangkan skor rata-rata pada kelas kontrol yaitu 10,27 dengan kategori sedang dari skor ideal 21. Hasil uji statistik menggunakan uji t' diperoleh bahwa $H_{1}$ diterima dan $H_{0}$ ditolak. Dengan demikian dapat disimpulkan bahwa terdapat perbedaan hasil belajar fisika antara peserta didik yang diajar dengan pembelajaran inkuiri terbimbing dengan yang diajar secara konvensional.
\end{abstract}

Kata Kunci: Pembelajaran Inkuiri Terbimbing, Hasil Belajar Fisika

\begin{abstract}
This research was a True Experimental Design research that using Posttest-Only Control Design. This study aims to describe the score of learning outcomes on cognitive aspects with four indicators, namely knowledge, understanding, application and analysis, between students taught by guided inquiry learning and those taught conventionally, and analyzing differences in learning outcomes of students taught by guided inquiry learning and conventionally learning. This research was conducted in Makassar State High School 3 Academic Year 2018/2019 with a sample of class XI MIPA 3 which amounted to 32 people as the experimental class and class XI MIPA 4 which amounted to 32 people as the control class. In the experimental class applied guided inquiry learning and in the control class conventional learning was applied. The results of the descriptive analysis of student physics learning outcomes tests obtained an average score in the experimental class of 12.79 with a high category, while the average score in the control class was 10.27 with a medium category of ideal scores 21. Statistical test results using the test $t$ 'is obtained that $\mathrm{HI}$ is accepted and $\mathrm{HO}$ is rejected. Thus it can be concluded that there are differences in the results of physics learning between students taught by guided inquiry learning with those taught conventionally.
\end{abstract}

Keywords: Guided Inquiry Learning, the results of studying physics 



\section{PENDAHULUAN}

Berdasarkan Undang-Undang No. 20 Tahun 2003 Tentang Sistem Pendidikan Nasional dalam Pasal 1 disebutkan,

"Pendidikan merupakan usaha sadar dan terencana untuk mewujudkan suasana belajar dan proses pembelajaran agar peserta didik secara aktif mengembangkan potensi dirinya untuk memiliki kekuatan spiritual keagamaan, pengendalian diri, kepribadian, kecerdasan, akhlak mulia, serta keterampilan yang diperlukan dirinya, masyarakat, bangsa dan negara". (Depdiknas,2017)

Berdasarkan undang-undang tersebut, diperlukan suatu proses pembelajaran yang dapat mendukung sesuai dengan tujuan pendidikan. Diantaranya yaitu dengan melaksanakan pembelajaran yang berpusat pada peserta didik, pembelajaran interaktif, membangun pembelajaran secara jejaring dimana peserta didik dapat menimba ilmu dari mana saja.

Salah satu upaya pemerintah dalam mewujudkan tujuan dari pendidikan tersebut ialah dengan melakukan penyempurnaan kurikulum pendidikan secara bertahap. Saat ini diberlakukan kurikulum baru secara Nasional, yaitu kurikulum 2013 yang telah direvisi. Kurikulum 2013 ini ditetapkan berdasarkan kebutuhan peserta didik. Dimana peserta didik dituntut aktif, kreatif, disiplin, serta memiliki tanggung jawab baik kepada dirinya sendiri maupun apa yang dikerjakan.

Proses pembelajaran diatas telah diatur dalam kurikulum 2013, pada Permendikbud No. 69 Tahun 2013 Tentang Kerangka Dasar dan Struktur Kurikulum SMA/MA, di mana pembelajaran pada kurikulum 2013 telah dirancang dengan pola pembelajaran aktif, interaktif, pola pembelajaraan secara jejaring, dan pembelajaran secara tim atau berkelompok. Alternatif pembelajaran yang berpotensi dan juga dianjurkan dalam kurikulum 2013 yaitu pembelajaran yang dilaksanakan dengan menggunakan pendekatan berbasis keilmuan. (Kemendikbud,2013)

Pembelajaran yang mengadopsi langkahlangkah saintis dalam membangun pengetahuan melalui metode ilmiah yang menekankan pada proses pencarian pengetahuan, melalui pengalaman belajar mengamati, menanya, mengumpulkan informasi/mencoba, mengasosiasi dan mengkomunikasikan. Salah satu model pembelajaran yang memiliki langkahlangkah saintis di dalamnya adalah model pembelajaran inkuiri.

Berdasarkan hasil observasi dan wawancara yang dilaksanakan pada 17 September 2018 di SMA Negeri 3 Makassar diperoleh informasi bahwa guru mata pelajaran fisika telah mencoba menggunakan model pembelajaran inkuiri, namun belum diketahui secara pasti bagaimana efektifitas dari pembelajaran tersebut. Selain itu informasi yang diperoleh dari guru mata pelajaran fisika yaitu model pembelajaran inkuiri dapat diterapkan di kelas XI MIPA SMA Negeri 3 Makassar karena peserta didik memiliki kemampuan berinkuiri hanya saja masih perlu bimbingan dari guru, oleh karena itu peneliti memilih salah satu jenis model pembelajaran inkuiri yaitu model pembelajaran inkuiri terbimbing.

Bonstter dan Marthen-Hansen (Anam, 2016:17) menyebutkan bahwa inkuiri terbimbing merupakan model pembelajaran dimana guru datang ke kelas dengan membawa masalah untuk dipecahkan oleh peserta didik, kemudian mereka 
dibimbing untuk menemukan cara terbaik dalam memecahkan masalah tersebut.

Model pembelajaran inkuiri terbimbing merupakan salah satu jenis dari pembelajaran inkuiri yang melibatkan peserta didik untuk menemukan jawaban terhadap masalah yang dikemukakan oleh guru dan tetap dibawah bimbingan intensif dari guru. Dalam pelaksanaannya, peserta didik dilibatkan dalam penyelidikan, mengidentifikasi konsep atau metode serta mendorong peserta didik dalam menemukan cara untuk memecahkan masalah yang di hadapi (Nugroho,2018).

Salah satu manfaat dari belajar melalui inkuiri terbimbing yaitu semua merasakan proses belajar mereka sendiri dari awal sampai akhir, tetapi yang lebih penting adalah kemandirian dalam penelitian dan pembelajaran, pengembangan berbagai keterampilan, dan keterampilan sosial serta bahasa dan membaca tertanam dalam pendekatan inkuiri terbimbing (Kuhlthau,2007:10)

Model pembelajaran inkuiri memiliki beberapa keunggulan dibandingkan dengan model pembelajaran lain yang pertama, dalam pembelajaran inkuiri menekankan pada pengembangan aspek kognitif, afektif, dan psikomotor secara seimbang, sehingga pembelajaran dianggap lebih bermakna. Kedua, memberikan ruang kepada peserta didik untuk belajar sesuai dengan gaya belajarnya. Ketiga, sesuai dengan perkembangan psikologi belajar modern yang menganggap belajar adalah proses perubahan tingkah laku berkat adanya pengalaman belajar secara langsung.

Dibandingkan dengan pembelajaran konvensional di sekolah tersebut yaitu ceramah bervariasi, melalui model pembelajaran inkuiri terbimbing peserta didik dapat lebih aktif dalam proses belajar mengajar dan dapat mengembangkan pengetahuannya sendiri namun tetap dalam bimbingan intensif guru, sehingga belajar menjadi bermakna dan hasil belajar peserta didik dapat meningkat. Hal ini selaras dengan penelitian yang telah dilakukan oleh Yulianingsih dan Hadisaputro (2013:155) tentang keefektifan pendekatan student centered learning dengan inkuiri terbimbing untuk meningkatkan hasil belajar, diperoleh bahwa hasil belajar peserta didik yang diberi pembelajaran dengan pendekatan student centered learning dengan inkuiri terbimbing lebih baik dengan presentasi skor hasil belajar sebesar 93,94\% daripada hasil belajar yang diberi pembelajaran dengan metode ceramah dengan presentasi skor hasil belajar 78,79\%.

\section{METODE}

Jenis penelitian yang digunakan adalah True experimental Design dengan menggunakan Posttest-Only Control Design sebagai desain penelitian. Penelitian ini dilaksanakan pada bulan Agustus 2018 sampai Mei 2019 dan lokasi penelitian ini bertempat di SMAN 3 Makassar. Populasi penelitian ini adalah seluruh kelas XI SMA Negeri 3 Makassar yang berjumlah 256 orang.

Teknik pengambilan sampel pada penelitian ini menggunakan simple random sampling. Hal ini dilakukan agar tidak mengganggu proses pembelajaran peserta didik dengan pertimbangan bahwa kedudukan peserta didik di dalam kelas ditetapkan tanpa melihat peringkat nilai, jenis kelamin, golongan peserta didik. Sampel dalam penelitian ini adalah peserta didik kelas XI MIPA 3 dan kelas XI MIPA 4. Variabel pada penelitian ini yaitu model pembelajaran inkuiri terbimbing dan model pembelajaran konvensional sebagai variabel bebas dan hasil belajar fisika peserta didik kelas 
XI MIPA SMA Negeri 3 Makassar sebagai variabel terikat.

Instrument penelitian yang digunakan pada penelitian ini adalah tes tertulis berbentuk pilihan ganda pada pokok bahasan suhu dan kalor, yang didasarkan pada kompetensi dasar dan indikator pembelajaran meliputi jenjang pengetahuan $(\mathrm{C} 1)$, pemahaman $(\mathrm{C} 2)$, aplikasi (C3), dan menganalisis (C4). Perangkat pembelajaran yang digunakan pada penelitian ini adalah Rencana Pelaksanaan Pembelajaran (RPP) dan Lembar Kerja Peseta Didik (LKPD). Prosedur penelitian ini terbagi menjadi tiga tahap yaitu tahap persiapan yang terdiri dari observasi, wawancara dan penyusunan perangkat pembelajaran, tahap pelaksanaan dimana pembelajaran inkuiri terbimbing diberikan pada kelas eksperimen dan tahap akhir yaitu penyusunan laporan hasil penelitian. Dalam penelitian ini data yang diperoleh dianalisis dengan menggunakan dua macam statistik yaitu analisis statistik deskriptif yang meliputi penghituungan skor rata-rata, standar deviasi, varians serta pengkategorian skor. Dan untuk statiktik inferensial meliputi uji normalitas, uji homogenitas dan uji hipotesis, karena data yang diperoleh terdistribusi normal dan tidak homogen maka uji hipotesis yang digunakan adalah uji t' dengan persamaan sebagai berikut:

$$
\mathrm{t}^{\prime}=\frac{\mathrm{x}_{1}-\mathrm{x}_{2}}{\sqrt{\left(\frac{\mathrm{s}_{1}{ }^{2}}{\mathrm{n}_{1}}+\frac{\mathrm{s}_{2}{ }^{2}}{\mathrm{n}_{2}}\right)}}
$$

dengan :

$\bar{x}_{1}=$ rata-rata skor kelompok eksperimen

$\bar{x}_{2}=$ rata-rata skor kelompok kontrol

$S_{I}=$ standar deviasi kelompok eksperimen

$S_{2}=$ standar deviasi kelompok kontrol

$n_{1}=$ jumlah sampel kelompok eksperimen

$n_{2}=$ jumlah sampel kelompok kontrol
Kriteria pengujian adalah: terima hipotesis $\mathrm{H}_{0}$ jika

$$
\frac{-w_{1} t_{1}+w_{2} t_{2}}{w_{1}+w_{2}}<t^{\prime}<\frac{w_{1} t_{1}+w_{2} t_{2}}{w_{1}+w_{2}}
$$

Dengan: $w_{1}=\frac{s_{1}{ }^{2}}{n_{1}}, w_{2}=\frac{s_{2}{ }^{2}}{n_{2}}$

$$
\begin{aligned}
& t_{1}=t\left(1-\frac{1}{2 \alpha}\right),\left(n_{1}-1\right) \\
& t_{2}=t\left(1-\frac{1}{2 \alpha}\right),\left(n_{2}-1\right)
\end{aligned}
$$

(Sudjana, 2005: 241)

\section{HASIL DAN PEMBAHASAN}

a. Hasil

Hasil analisis deskriptif menunjukkan deskripsi tentang skor hasil belajar fisika peserta didik masing-masing kelompok penelitian. Adapun gambaran skor hasil belajar fisika peserta didik antara dua kelas yaitu kelas eksperimen yang diajar dengan model pembelajaran inkuiri terbimbing dan kelas kontrol yang diajar dengan model pembelajaran konvensional adalah sebagai berikut:

Tabel 1. Skor Statistik Deskriptif Hasil Belajar Fisika Peserta Didik Kelas Kontrol Dan Kelas Eksperimen

\begin{tabular}{ccc}
\hline \multirow{2}{*}{ Statistik } & \multicolumn{2}{c}{$\begin{array}{c}\text { Nilai Statistik } \\
\text { Hasil Belajar Fisika }\end{array}$} \\
\cline { 2 - 3 } & $\begin{array}{c}\text { Kelas } \\
\text { Eksperimen }\end{array}$ & $\begin{array}{c}\text { Kelas } \\
\text { Kontrol }\end{array}$ \\
\hline Jumlah Sampel & 32 & 32 \\
\hline $\begin{array}{c}\text { Skor maksimum } \\
\text { ideal }\end{array}$ & 21 & 21 \\
\hline $\begin{array}{c}\text { Skor minimum } \\
\text { ideal }\end{array}$ & 0 & 0 \\
\hline Skor tertinggi & 17 & 15 \\
\hline Skor terendah & 10 & 10 \\
\hline Rentang Skor & 7 & 10,27 \\
\hline Skor rata-rata & 12,79 & 3,56 \\
\hline Standar deviasi & 1,80 & 12,73 \\
\hline Varians & 3,26 & $(\mathrm{Ruanti} 2$
\end{tabular}

Skor hasil belajar fisika peserta didik kelas eksperimen dan kelas kontrol dikategorikan berdasarkan adopsi dari Riduwan (2011: 41) tentang pengkategorian hasil belajar, maka dapat 
dibuat tabel pengkategorian skor hasil belajar sebagai berikut.

Tabel 2. Pengkategorian dan Persentase Skor Hasil Belajar Peserta Didik Kelas Eksperimen dan Kelas Kontrol SMA Negeri 3 Makassar

\begin{tabular}{cccccc}
\hline \multirow{2}{*}{$\begin{array}{c}\text { Interval } \\
\text { Skor }\end{array}$} & Kategori & Krekuensi & $\begin{array}{c}\text { Persentasi } \\
\mathbf{( \% )}\end{array}$ & Frekuensi & $\begin{array}{c}\text { Persentasi } \\
(\%)\end{array}$ \\
\cline { 3 - 6 } $0-4$ & $\begin{array}{c}\text { Sangat } \\
\text { Rendah }\end{array}$ & 0 & 0 & 0 & 0 \\
\hline $5-8$ & Rendah & 0 & 0 & 10 & 31,3 \\
\hline $9-12$ & Sedang & 15 & 46,9 & 9 & 28,1 \\
\hline $13-16$ & Tinggi & 16 & 50,0 & 13 & 40,6 \\
\hline $17-21$ & $\begin{array}{c}\text { Sangat } \\
\text { Tinggi }\end{array}$ & 1 & 3,10 & 0 & 0 \\
\hline & & & & (Ruanti, 2019)
\end{tabular}

Indikator hasil belajar pada aspek kognitif yang dinilai pada penelitian ini adalah pengetahuan, pemahaman, aplikasi dan analisis. Hasil analisis tiap indikator hasil belajar adalah sebagai berikut.

Tabel 3 Persentase Skor Hasil Belajar Peserta Didik Kelas XI IPA SMA Negeri 3 Makassar

\begin{tabular}{ccccc}
\hline \multirow{2}{*}{ Indikator } & \multicolumn{2}{c}{ Kelas } & \multicolumn{2}{c}{ Kelas Kontrol } \\
\cline { 2 - 5 } & $\begin{array}{c}\text { Skor } \\
\text { rata- } \\
\text { rata }\end{array}$ & $\begin{array}{c}\text { Pres- } \\
\text { entasi } \\
(\%)\end{array}$ & $\begin{array}{c}\text { Skor } \\
\text { rata- } \\
\text { rata }\end{array}$ & $\begin{array}{c}\text { Presen- } \\
\text { tasi (\%) }\end{array}$ \\
\hline $\begin{array}{c}\text { Pengetahuan/ } \\
\text { Ingatan (C1) }\end{array}$ & 1,56 & 78,12 & 1,31 & 65,62 \\
\hline $\begin{array}{c}\text { Pemahaman } \\
\text { (C2) }\end{array}$ & 2,65 & 66,41 & 2,62 & 65,63 \\
\hline Aplikasi (C3) & 4,91 & 61,33 & 3,84 & 48,05 \\
\hline Analisis (C4) & 3,63 & 51,79 & 2,65 & 37,95 \\
\hline
\end{tabular}

(Ruanti,2019)

Selain dianalisis secara deskriptif, data hasil penelitian juga dianalisis secara inferensial dengan statistik uji-t' yang bertujuan untuk pengujian hipotesis. Sebelum digunakan uji-t, terlebih dahulu dilakukan uji normalitas dan homogenitas.

Hasil perhitungan untuk kelas eksperimen yang diajar menggunakan model pembelajaran inkuiri terbimbing diperoleh $X$
${ }^{2}$ hitung $=2,379$. Untuk taraf signifikan $\alpha \alpha=0.05$ dan $\mathrm{dk}=\mathrm{k}-1=5-1=4$, maka diperoleh $x_{\text {tabel }}^{2}=x$ ${ }_{(0,95)(4)}=9,48$. Dengan demikian $X_{\text {hitung }}^{\boldsymbol{2}} x$ ${ }^{2}$ hitung $<x{ }_{\text {tabel }}(2,379<9,48)$ yang berarti skor hasil belajar fisika peserta didik berasal dari populasi yang berdistribusi normal. Demikian pula halnya dengan kelas kontrol yang diajar dengan menggunakan pembelajaran konvensional diperoleh $X^{2}$ hitung $=9,767$. Untuk $\alpha$ $\alpha=0.05$ dan $\mathrm{dk}=\mathrm{k}-1=6-1=5$, maka diperoleh $x_{\text {tabel }}^{2}=x_{(0,95)(5)}^{2}=11,07$. Dengan demikian $X_{\text {hitung }}^{2} \quad x^{2}{ }_{\text {hitung }}<x^{2}{ }_{\text {tabel }}(9,767<11,07) \quad$ yang berarti skor hasil belajar fisika peserta didik berasal dari populasi yang berdistribusi normal.

Hasil pengujian homogenitas varians data skor hasil belajar fisika untuk kelas eksperimen yang diajar menggunakan model pembelajaran inkuiri terbimbing dan kelas kontrol yang diajar menggunakan pembelajaran konvensional menggunakan uji F. Berdasarkan analisis, dengan taraf nyata $\alpha=0,05$ diperoleh nilai $F_{\text {hitung }}$ dan $F_{\text {tabel }}$ untuk skor hasil belajar fisika, $F_{\text {hitung }}=3,57$ dengan $F_{\text {tabel }}=1,82$. Karena $F_{\text {hitung }}>F_{\text {tabel }}$ maka ini menunjukkan bahwa data skor hasil belajar fisika peserta didik kelas eksperimen dan kontrol memiliki varians yang berbeda atau tidak homogen.

Berdasakan uji prasyarat yaitu uji normalitas dan uji homogenitas diperoleh bahwa kelas eksperimen dan kelas kontrol mempunyai populasi yang terdistribusi normal namun varians datanya tidak homogen, sehingga pengujian hipotesis penelitian dilakukan dengan menggunakan uji-t'. berdasarkan persamaan (3.10) diperoleh nilai $t$ ' untuk skor hasil belajar fisika sebesar 3,56 sedangkan $t_{\text {tabel }}$ pada taraf $\mathrm{dk}_{1}$ $=\mathrm{dk}_{2}=31$ adalah sebesar 2,03. 
Hasil analisis diperoleh nilai t' tidak berada pada rentang -2,03 sampai dengan 2,03. Dengan demikian hipotesis $\mathrm{H}_{0}$ ditolak dan $\mathrm{H}_{1}$ diterima sehingga dapat disimpulkan bahwa terdapat perbedaan yang signifikan terhadap skor hasil belajar fisika peserta didik yang diajar dengan menggunakan model pembelajaran inkuiri terbimbing dengan peserta didik yang tidak diajar dengan menggunakan model pembelajaran inkuiri terbimbing.

\section{b. Pembahasan}

Berdasarkan hasil analisis statistik secara deskriptif menunjukkan perbandingan skor hasil belajar peserta didik antara kelas eksperimen dan kelas kontrol. Dimana skor rata-rata yang diperoleh peserta didik pada kelas eksperimen lebih tinggi dibandingkan dengan kelas kontrol. Dilihat pada tabel pengkategorian skor hasil belajar fisika, peserta didik kelas eksperimen dan kontrol tersebar dalam tiga pengkategorian yaitu kategori rendah, sedang dan tinggi. Berdasarkan hasil analisis tersebut terlihat bahwa secara analisis deskriptif kelas eksperimen berada pada kategori tinggi dan kelas kontrol berada pada kategori sedang. Berdasarkan hasil analisis inferensial terbukti bahwa terdapat perbedaan yang signifikan antara kedua kelas. Hal ini menunjukkan perbedaan skor rata-rata antar kedua kelas jika diterapkan pada populasi.

Perbedaan antara skor hasil belajar peserta didik pada kelas eksperimen dan kelas kontrol dimana kelas eksperimen lebih tinggi dibandingkan kelas kontrol, hal ini dapat dikaitkan dengan teori tentang faktor-faktor yang mempengaruhi proses dan hasil belajar dimana selain faktor internal yaitu fisiologi ( fisik dan panca indra) dan psikologi (bakat, minat dan kecerdasan) terdapat faktor eksternal yaitu lingkungan, kurikulum, guru, sarana dan prasarana. Model pembelajaran inkuiri terbimbing termasuk dalam faktor eksternal yang dapat mempengaruhi proses dan hasil belajar dimana peserta didik mendapatkan suasana belajar yang berbeda dari sebelumnya sehingga peserta didik pada kelas eksperimen lebih termotivasi dan menjadi lebih aktif dalam proses pembelajaran sehingga materi pembelajaran lebih bermakna dan dapat lebih lama diingat oleh peserta didik, hal ini berpengaruh pada meningkatkan hasil belajar peserta didik.

Dari uraian di atas, maka dapat disimpulkan bahwa pembelajaran fisika dengan menggunakan model pembelajaran inkuiri terbimbing lebih efektif dalam meningkatkan hasil belajar fisika peserta didik daripada pembelajaran dengan menggunakan model pembelajaran konvensional. Hasil penelitian ini selaras dengan hasil penelitian yang telah dilakukan oleh Yulianingsih dan Hadisaputro tentang keefektifan pendekatan student centered learning dengan inkuiri terbimbing untuk meningkatkan hasil belajar, yang menunjukkan hasil kurang lebih sama yaitu pembelajaran inkuiri terbimbing efektif dalam meningkatkan hasil belajar peserta didik.

\section{KESIMPULAN}

Berdasarkan hasil penelitian dan pembahasan, dapat disimpulkan sebagai berikut. Skor hasil belajar fisika peserta didik yang diajar dengan menggunakan model pembelajaran inkuiri terbimbing berada pada rentag skor 12 15 , yang berada pada kategori tinggi. Skor hasil belajar fisika peserta didik yang diajar dengan menggunakan model pembelajaran konvensional berada pada rentang skor $7-14$, yang berada pada kategori sedang. Terdapat perbedaan antara skor hasil belajar fisika peserta didik yang diajar menggunakan model pembelajaran inkuiri 
terbimbing dengan hasil belajar fisika peserta didik yang diajar dengan menggunakan model pembelajaran konvensional.

\section{DAFTAR RUJUKAN}

Anam Khoirul, M. (2016). Pembelajaran Berbasis Inkuiri. Yogyakarta: Pustaka Pelajar.

Depdiknas. (2017). Undang-Undang No. 20 Tahun 2003 Tentang Sistem Pendidikan Nasional. Jakarta: Dirjen Diknas.

Hadisaputro, \& Y (2013). Keefektifan Pendekatan Student Centered Learning Dengan Inkuiri Terbimbing Untuk Meningkatkan Hasil Belajar. Issn NO 22526609-Conservation University, 155.

Kemendikbud. (2013). Kerangka Dasar Dan Struktur Kurikulum Sma/Ma. Jakarta: Dirjen Diknas.
Kuhlthau, C. C. (2007). Guide Inquiry Learning In The 21th Century. London: Liberary Unlimited.

Nugroho, A. (2018). Higher Order Thinking Skills. Jakarta: Kompas Gramedia.

Ruanti Reni. (2019). Efektivitas Pembelajaran Inkuiri Terbimbing Dalam Fisika Pada Peserta Didik Kelas XI MIPA SMA Negeri 3 Makassar. Makassar: Universitas Negeri Makassar.

$$
\text { Riduwan. (2016). Dasar-Dasar }
$$

Statistika. Bandung: Alfabeta. 